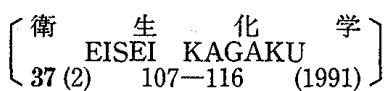

\title{
Production of Aflatoxins and Aflatoxicols by Aspergillus flavus and Aspergillus parasiticus and Metabolism of Aflatoxin $\mathbf{B}_{1}$ by Aflatoxin-non-producing Aspergillus flavus
}

\author{
Mitsuo Nakazato, ${ }^{a}$ Satoshi Morozumi, ${ }^{a}$ Kazuo Saito, ${ }^{a}$ Kenji Fujinuma, ${ }^{a}$ \\ Taichiro Nishima ${ }^{a}$ and Nobuhiko Kasal ${ }^{b}$ \\ Department of Food Hygiene and Nutrition, The Tokyo Metropolitan Research Laboratory of \\ Public Health, ${ }^{a}$ Hyakunincho, Shinjuku-ku, Tokyo 169, Japan and Department of \\ Microbial Chemistry, School of Pharmaceutical Sciences, Showa University, ${ }^{b}$ \\ Hatanodai, Shinagawa-ku, Tokyo 142 Japan
}

(Received October 3, 1990)

The production of aflatoxin (AF) groups $\left(B_{1}, B_{2}, G_{1}, G_{2}, M_{1}, M_{2}, P_{1}\right.$ and $\left.Q_{1}\right)$ and aflatoxicol (AFL) groups (A and B) by AF-producing Aspergillus flavus and $A$. par. asiticus isolated from various foods, and the metabolism of $A F B_{1}$ to $A F M_{1}, A F P_{1}, A F$ $\mathrm{Q}_{1}$, AFL-A and AFL-B by AF-non-producing A. flavus also isolated from various foods, were studied. A simple and rapid method for the analysis of the 10 kinds of toxins was developed.

Toxins produced in culture were extracted with chloroform, separated into AF and AFL fractions by a silica gel cartridge column, then assayed by high performance liquid chromatography (HPLC).

$A F M_{1}, A F M_{2}, A F L-A$ and AFL-B were detected in addition to AF $B_{1}$ and $A F B_{2}$ in nearly all of the cultures inoculated with $A F$-producing $A$. flavus. The same groups were detected in addition to $A F B_{1}, A F B_{2}, A F G_{1}$ and $A F G_{2}$ in the cultures inoculated with A. parasiticus. The time courses of $A F M_{1}$ and $A F M_{2}$ production were almost the same as those of $A F B_{1}, A F B_{2}, A F G_{1}$ and $A F G_{2}$. AFLs tended to appear after AFs had accumulated in the cultures. $A F P_{1}$ and $A F Q_{1}$ were not detected at all.

$\mathrm{AF} \mathrm{B}_{1}$ added to the cultures was metabolized by all strains of non-AF-producing $A$. flavus. AFL-A and AFL-B were the common metabolites in all of the cultures. However, no strains which converted $A F B_{1}$ to $A F M_{1}, A F P_{1}$ and $A F Q_{1}$ were observed.

Keywords—-mycotoxin; aflatoxin ; aflatoxicol ; Aspergillus flavus ; Aspergillus parasiticus ; HPLC ; fluorescence detector ; silica gel cartridge column ; MS

\section{Introduction}

Aflatoxins are a group of structurally related toxic bisfuranocoumarins produced as secondary metabolites by certain strains of Aspergillus flavus and $A$. parasiticus. Typical aflatoxins produced by these species are $B_{1}$, $B_{2}, G_{1}$, and $G_{2}$, frequently found as natural contaminants of both human and animal foodstuffs. These species are also well known ${ }^{1)}$ to produce some aflatoxin (AF)-related com- pounds such as $M_{1}, M_{2}, B_{2 a}, G_{2 a}$, Parasiticol, etc. Natural contamination by these toxins, however, is not generally found. Among these metabolites, $\mathrm{AF} \mathrm{B}_{1}$, which is produced most abundantly by these Aspergillus species is the most highly carcinogenic, and it has been the subject of numerous studies. In $\mathrm{AF} \mathrm{B}_{1}$ degradation or metabolism studies, several derivatives have been identified. $A F M_{1}, A F P_{1}, A F$ $\mathrm{Q}_{1}$ and aflatoxicol (AFL) - A are well known ${ }^{1)}$ as metabolites in animals. However, it is 
known that $\mathrm{AF} \mathrm{B}_{1}$ is also metabolized by many species of fungi, ${ }^{2)}$ in which $\mathrm{AF} \mathrm{B}_{2 \mathrm{a}}{ }^{3,4)}$ AFL-A ${ }^{5-8)}$ and AFL-B ${ }^{5-8)}$ have been identified as metabolites.

The authors found that maize naturally contaminated with high concentrations with $\mathrm{AF} \mathrm{B}_{1}$ and $\mathrm{AF} \mathrm{B}_{2}$ was simultaneously contaminated with AF $\mathrm{M}_{1}$, AF $\mathrm{M}_{2}$, AFL-A and AFL-B,${ }^{9)}$ and found that $A$. flavus isolated from maize contaminated with AFs and AFLs produced $A F M_{1}$, AFL-A and AFL-B in addition to $\mathrm{AF} \mathrm{B}_{1}$ and $\mathrm{AF} \mathrm{B}_{2} \cdot{ }^{10)}$ Furthermore, we reported that several other fungi $(A$. niger, Eurotium herbariorum, Rhizopus sp., etc.) isolated from the same maize had fairly strong ability to convert $A F B_{1}$ to $A F L .{ }^{8)}$

If $\mathrm{AF} \mathrm{B}_{1}$-producing $A$. flavus and $A$. parasiticus have the ability to produce various $A F B_{1}$ derivatives or to convert $A F B_{1}$ to $A F$ $B_{1}$ derivatives, these $A F B_{1}$-producing strains should be the first suspects as strains causing the contamination of the $A F B_{1}$ derivatives. However, little is known about the production abilities of $A F B_{1}$ derivatives or the conversion abilities of $A F B_{1}$ to $A F B_{1}$ derivatives in AF $\mathrm{B}_{1}$-producing $A$. flavus and $A$. parasiticus.

This report deals with the production of the well characterized metabolites of $A F B_{1}$, i.e., $\mathrm{AF} \mathrm{P}_{1}, \mathrm{AF} \mathrm{Q}_{1}$, AFL-A and AFL-B, as well as those of $A F B_{1}, A F B_{2}, A F G_{1}, A F G_{2}, A F$ $\mathrm{M}_{1}$ and $\mathrm{AF} \mathrm{M}_{2}$ of $A$. flavus and $A$. parasiticus isolated from various commercial foods. The conversion of $\mathrm{AF}_{1}$ to the above mentioned $\mathrm{AF} \mathrm{B}_{1}$ derivatives by $\mathrm{AF}$-non-producing $A$. flavus is also described. Further, a simple method for isolation and determination of these 10 toxins by high performance liquid chromatography (HPLC) is given.

\section{Materials and Methods}

Organisms - The production of AFs and AFLs was investigated in AF-producing $A$. flavus (18 strains) and $A$. parasiticus (3 strains) isolated from commercial foods. The metabolism of AF $\mathrm{B}_{1}$ was investigated in 3 strains of $A$. flavus which lost AF productivity at the subculture stage and 4 strains of $A$. flavus without AF productivity at the isolation stage.

Culture Medium and Reagents _ L Low-salt (SL) medium ${ }^{11)}$ was used to study the production of AFs and AFLs by AF-producing A. flavus and A. parasiticus and the metabolism of $\mathrm{AF} \mathrm{B}_{1}$ by AF-non-producing $A$. flavus. AFL-A, AFL-B, AF $B_{1}$, AF $B_{2}, A F G_{1}, A F G_{2}$, AF $M_{1}$, AF $M_{2}$, AF $P_{1}$ and $A F Q_{1}$, were obtained from Makor Chemicals, Ltd. (Jerusalem, Israel). These toxins were used as standard without refining.

Inoculation and Incubation _ _ All strains were inoculated onto potato dextrose agar (PDA) slants and cultivated for 7 days at $25^{\circ} \mathrm{C}$ until well sporulated. The spores were harvested in $0.001 \%$ Tween 80 to a density of $10^{4}$ spores per ml. One hundred microliters of the spore suspension from AF-producing strains was inoculated onto $10 \mathrm{ml}$ of SL medium, and the medium cultured for 5,10 , 15 and 20 days at $25^{\circ} \mathrm{C}$ under stationary conditions. After incubation, the production of $A F B_{1}$, $A F B_{2}, A F G_{1}, A F G_{2}, A F M_{1}, A F M_{2}, A F P_{1}, A F$ $Q_{1}$ AFL-A and AFL-B was investigated. To study the conversion of $A F B_{1}$ to $A F M_{1}, A F P_{1}, A F Q_{1}$, AFL-A and AFL-B, $100 \mu 1$ of the spore suspension prepared from AF-non-producing $A$. flavus was inoculated onto $10 \mathrm{ml}$ of SL culture medium containing $\mathrm{AF} \mathrm{B}_{1}(2000 \mathrm{ng} / \mathrm{ml})$, and cultured under the same conditions described above. After the incubation, levels of $A F B_{1}$ metabolites were investigated.

Extraction of AFs and AFLs and Preparation of Test Solution — Five grams of sodium chloride and $100 \mathrm{ml}$ of chloroform were added to the whole culture. The mixture was homogenized at $10000 \mathrm{rpm}$ for $10 \mathrm{~min}$ and centrifuged to separate the chloroform layer. The chloroform layer was then dehydrated with anhydrous sodium sulfate and filtered through filter paper. The solvent was concentrated to approximately $5 \mathrm{ml}$ under reduced pressure. For separation into $\mathrm{AF}$ and AFL groups, the concentrated solvent was applied to a Mega Bond Elut Silica gel column (Sorbent mass, $5 \mathrm{~g}$; Analytichem International, Harbor City, CA, U.S.A.) previously washed with $20 \mathrm{ml}$ of chloroform. The column was washed with $20 \mathrm{ml}$ 
of $n$-hexane, and then AFLs were eluted with 20 $\mathrm{ml}$ of ethylether. The remaining AFs were eluted with $40 \mathrm{ml}$ of methanol-chloroform $(3: 97)$. The solvent was evaporated from the eluates, and residues were dissolved in an appropriate amount of chloroform for HPLC.

HPLC Conditions - The HPLC system was composed of a 880-PU pump (Jasco), a 470type scanning fluorescence detector (Waters Associates, Milford, Massachusetts, U.S.A.), and a C-R6A data processing unit (Shimadzu). HPLC conditions for the determination of the $\mathrm{AF}$ group, i.e., $B_{1}, B_{2}, G_{1}, G_{2}, M_{1}, M_{2}, P_{1}$ and $Q_{1}$ were as follows : column, Finepak SIL-5 $(5 \mu \mathrm{m}, 25 \mathrm{~cm} \times$ $4.6 \mathrm{~mm}$ I.D., Jasco) ; mobile phase, tolueneethylacetate-formic acid-methanol $(700: 70: 15$ : 20 ) flow rate, $1.0 \mathrm{ml} / \mathrm{min}$; detection, fluorescence (excitation $365 \mathrm{~nm}$, emission $425 \mathrm{~nm}$ ). HPLC conditions for the determination of AFL-A and AFL-B were as follows: column, Finepak SIL-5 (5 $\mu \mathrm{m}, 25 \mathrm{~cm} \times 4.6 \mathrm{~mm}$ I.D.) ; mobile phase, chloroform-methanol ( $99: 1)$; flow rate, $1.0 \mathrm{ml} /$ $\mathrm{min}$; and detection, fluorescence (excitation 330 $\mathrm{nm}$, emission $390 \mathrm{~nm}$ ). Chloroform (Kanto Chemical CO.) containing amilene as a stabilizer was used as the main component of the HPLC mobile phase.

Confirmation of AFs and AFLs_- AFs were confirmed by the excitation and emission spectra of the HPLC peaks. The spectra were compared with those of standard substances. AFLs were confirmed by mass spectrometry (MS). AFL samples for HPLC were further divided into AFL-A and AFL-B fractions by normal phase HPLC with chloroform-methanol $(100: 0.5)$ as the mobile phase. The respective fractions were concentrated to $50-100 \mu \mathrm{g} / \mathrm{ml}$ AFL in chloroform, and $1 \mu 1$ of the fraction was applied to MS by direct introduction (DI).

MS Conditions _- Mass spectrometer, TSQ 70 (Finigan MAT, San Jose, CA, U.S.A.) ; ionization mode, electron ionization (EI) ; ion source temp., $150^{\circ} \mathrm{C}$; ionization voltage, $70 \mathrm{eV}$; emission current, $700 \mu \mathrm{A}$; detector voltage, $1000 \mathrm{~V}$.

\section{Results and Discussion \\ 1. Analytical Conditions \\ For analysis of metabolites in the culture,} 8 types of $A F$, i.e., $B_{1}, B_{2}, G_{1}, G_{2}, M_{1}, M_{2}, P_{1}$ and $\mathrm{Q}_{1}$, and 2 types of AFL, i.e., AFL-A and AFL-B, were selected as the subjects of investigation. Optimum conditions for extraction of the toxins from cultures and for their isolation by HPLC were studied.

1) Conditions for Extraction of AFs and AFLs - Ten types of toxin were recovered by chloroform extraction ${ }^{10)}$ from the cultures. Five grams of sodium chloride and $100 \mathrm{ml}$ of chloroform were added to $10 \mathrm{ml}$ of SL culture medium containing $5 \mathrm{ppm}$ of each toxin. The mixture was homogenized at $10000 \mathrm{rpm}$ for $10 \mathrm{~min}$, resulting in over $95 \%$ recoveries of AFs and AFLs. Therefore, chloroform was considered the most suitable extraction solvent.

2) HPLC Conditions for AFs and AFLs - AFs and AFLs were simultaneously determined with a HPLC fluorescence detector. It is known ${ }^{12)}$ that $A F B_{1}$ and $A F G_{1}$ in reverse phase solvents and $A F B_{1}$ and $A F$ $\mathrm{B}_{2}$ in normal phase solvents consisting mainly of $n$-hexane or chloroform emit very weak fluorescence. Therefore, in general, $A F B_{1}$ and $A F G_{1}$ were converted to the hemiacetals, $A F B_{2 a}$ and $A F G_{2 a}$, in order to intensify their fluorescence in reverse phase solvents, and were measured by reverse phase HPLC with a fluorescence detector. ${ }^{13-15)}$ This method is only applicable to some AFs, however, being unsuitable for the simultaneous analysis of various toxins. Manabe et $a l .{ }^{16)}$ found that the fluorescence intensities of $A F B_{1}$ and $A F B_{2}$ were increased by the addition of acids to the mobile phase, and performed a high sensitivity analysis of $A F B_{1}, A F B_{2}, A F G_{1}$ and $A F$ $\mathrm{G}_{2}$ by fluorescence using a silica gel column and toluene-ethylacetate-formic acid-methanol as the mobile phase. We first determined whether or not simultaneous determination of the $10 \mathrm{AFs}$ and AFLs would be feasible under 
these conditions, and found that the fluorescence of AFs and AFLs was strong enough in this mobile phase to enable detection at high sensitivity. However, for the reciprocal separation of each toxin, it was necessary to modify the solvent composition in the mobile phase. In particular, the ethylacetate concentration in the mobile phase greatly influenced the separation of $8 \mathrm{AFs}$ (Fig. 1). When the solvent composition of this mobile phase was $700: 70: 15: 20$, the $8 \mathrm{AFs}$ were isolated in a short time (Fig. 2). However, AFL-A and AFL-B maintained the exact same retention time, being eluted under such conditions first (in about 8 minutes). Furthermore, it is also known that parts of AFL-A and AFL-B react with methanol in the presence of formic acid in the mobile phase. They appear as new peaks at a retention time of about 4 to 5

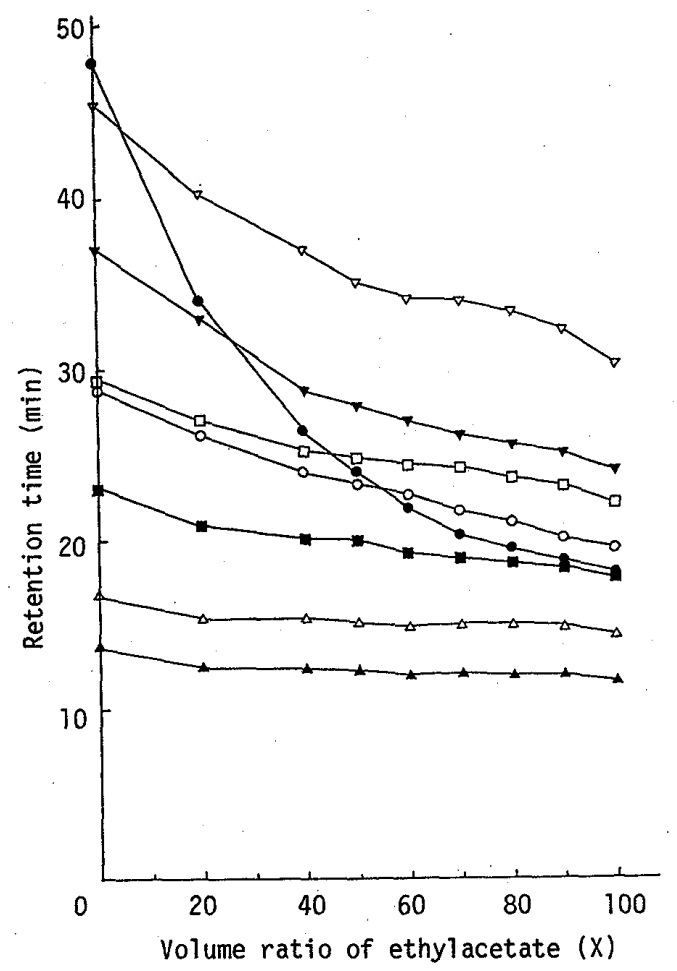

Fig. 1. Effect of the Volume Ratio of Ethylacetate on the Retention time of Aflatoxins

mobile phase; toluene-ethylacetate-formic acid-methanol $(700: \mathrm{X}: 15: 20)$.

- : aflatoxin $B_{1}, \triangle$ : aflatoxin $B_{2},-1$ - aflatoxin $G_{1}$, $\square-$ : aflatoxin $G_{2}, \rightarrow-$ : aflatoxin $M_{1}, \neg$ : aflatoxin $M_{2}$, - : aflatoxin $\mathrm{P}_{1},-\mathrm{O}^{-}$: aflatoxin $\mathrm{Q}_{1}$. minutes. The retention time of these new peaks is shorter than those of AFL derivatives which react with ethanol. Cole et al. $\left.{ }^{6}\right)$ reported that parts of AFL-A and AFL-B reacted with ethanol in the eluting solvent and were respectively converted to AFL-O. ethylether $\mathrm{A}$ and $\mathrm{AFL}-\mathrm{O}$-ethylether $\mathrm{B}$ during silica gel column chromatography. This is similar to the appearance of the new AFL derivatives in the present investigation. Therefore, it was considered that the new derivatives were AFL- $O$-methlyether $\mathrm{A}$ and AFL-O-methylether B, respectively. Accordingly, AFL could not be assayed in this mobile phase. Assay of AFL-A and AFL-B was thus carried out under different conditions previously reported by the authors, ${ }^{8)} i . e$., using silica gel for the column and chloroformmethanol $(99: 1)$ as the mobile phase. Under these conditions, AFL-A and AFL-B were very well separated (Fig. 3). However, since the retention time of $A F B_{1}$ was very close to that of AFL-A, the complete isolation of AFL-A from AF $B_{1}$ was almost impossible. Thus, both the AFL and AF groups required fractionation prior to HPLC.

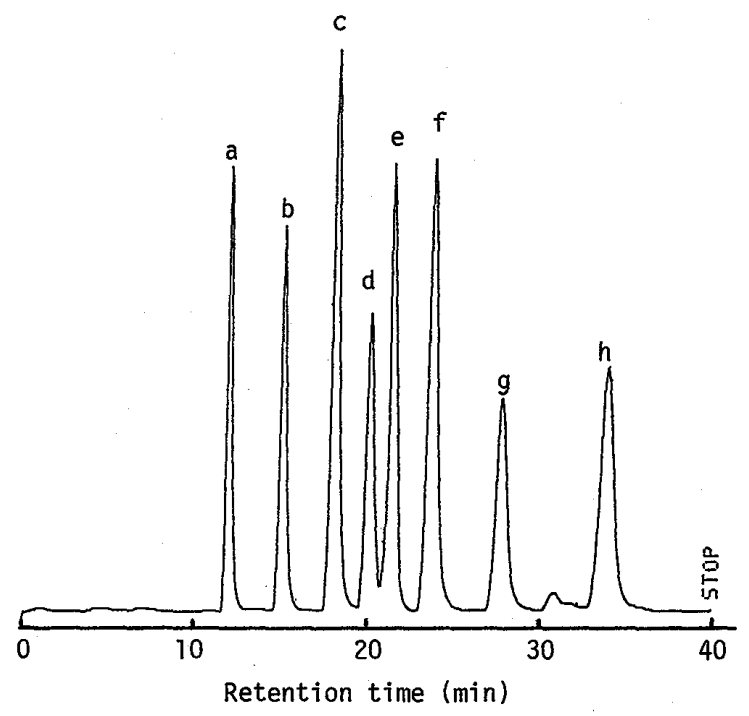

Fig. 2. High Performance Liquid Chromatogram of Aflatoxins

a : aflatoxin $B_{1}(20 \mathrm{ng}), \mathrm{b}$ : aflatoxin $\mathrm{B}_{2}(10 \mathrm{ng}), \mathrm{c}$ : aflatoxin $G_{1}(10 \mathrm{ng}), \mathrm{d}$ : aflatoxin $P_{1}(20 \mathrm{ng}), \mathrm{e}$ : aflatoxin $Q_{1}(40 \mathrm{ng})$, $\mathrm{f}$ : aflatoxin $\mathrm{G}_{2}(5 \mathrm{ng}), \mathrm{g}$ : aflatoxin $\mathrm{M}_{1}(20 \mathrm{ng}), \mathrm{h}$ : aflatoxin $\mathrm{M}_{2}$ (30 ng). 


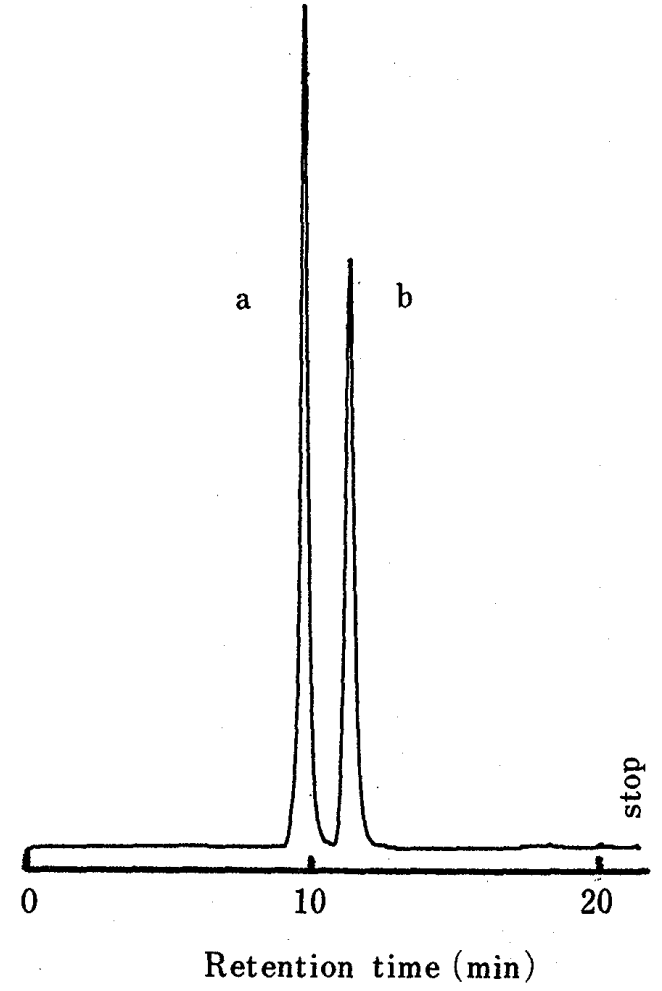

Fig. 3. High Performance Liquid Chromatogram of Aflatoxicols

a: aflatoxicol A (10 $\mathrm{ng}), \mathrm{b}$ : aflatoxicol B (8 $\mathrm{ng})$.

3) Pretreatment with Silica Gel Cartridge Column —We fractionated 2 AFLs and 6 AFs $\left(B_{1}, B_{2}, G_{1}, G_{2}, M_{1}\right.$ and $\left.M_{2}\right)$ by silica gel column chromatography, and reported that because only AFL-A and AFL-B are eluted by ether, fractionation of AFLs and AFs is feasible. ${ }^{17)}$ We applied this method to the analysis of the 2 AFLs and the 8 AFs with the silica gel cartridge column. AFL retained in the column was eluted completely in $20 \mathrm{ml}$ of ether, but AF was hardly eluted. AFs were eluted with a mixture of chloroform-methanol $(9: 1)$. AF $B_{1}$ and $A F B_{2}$ were eluted completely in $20 \mathrm{ml}$, while other AFs required 30 to $35 \mathrm{ml}$ of solvent to be eluted completely. We thus selected $40 \mathrm{ml}$ as the elution volume. With the cartridge column, the clean-up time was shortened notably and the amount of clean-up solvent was decreased markedly (1/ $5-1 / 10)$, compared with the previous method. ${ }^{17)}$

\section{AF and AFL Productivity of AF-Pro- ducing $A$. flavus and $A$. parasiticus}

The production of the AF group, i.e., $\mathrm{B}_{1}$, $B_{2}, G_{1}, G_{2}, M_{1}, M_{2}, P_{1}$ and $Q_{1}$, as well as AFL-A and AFL-B by AF-producing $A$. flavus and $A$. parasiticus was examined. In most of the cultures inoculated with AF-producing $A$. flavus, AF $\mathrm{B}_{1}, \mathrm{AF} \mathrm{B}_{2}, \mathrm{AF} \mathrm{M}_{1}, \mathrm{AF} \mathrm{M}_{2}$, AFL-A and AFL-B were detected. AF $B_{1}, A_{2} B_{2}, A F$ $\mathrm{G}_{1}, A F \mathrm{G}_{2}, A F M_{1}$ and $A F M_{2}$ were detected in the cultures of all 3 strains of $A$. parasiticus, and both AFL-A and AFL-B were detected in cultures inoculated with one of these strains. $\mathrm{AF} \mathrm{Q}_{1}$ and $\mathrm{AF} \mathrm{P}_{1}$ were not detected in any cultures inoculated with $A$. flavus or $A$. par asiticus.

In most of the cultures incubated for $15 \mathrm{~d}$, AFs were detected most abundantly, after which they tended to decrease. However, AFLs continued to increase until the 20th day. The production patterns of AFLs were distinct from those of AFs. Analytical results of AFs and AFLs in cultures inoculated with each strain are shown in Table $I$.

The correlation between $\mathrm{AF} \mathrm{B}_{1}$ production and that of $A F B_{2}, A F M_{1}$ and AFLs in 18 strains of $A$. flavus was studied on the 15 th day of incubation. Production of $A F B_{2}$ was nearly $1 / 20$ to $1 / 10$ of $A F B_{1}$, while that of $A F$ $M_{1}$ was about $1 / 100$ to $1 / 200$ of $A F B_{1}$. The correlation coefficient between $A F B_{1}$ and $A F$ $\mathrm{B}_{2}$ was fairly high at 0.957 and that between $A F B_{1}$ and $A F M_{1}$ was also reasonably noteworthy at 0.864 . Furthermore, when the production of each toxin was studied over time, $A F M_{1}$ and $A F M_{2}$ had almost identical patterns to those of $A F B_{1}$ and $A F B_{2}$. Yabe et $a l .{ }^{18,19)}$ have reported that $A F B_{1}$ and $A F G_{1}$ are synthesized from dimethyl sterigmatocystin, and that $A F B_{2}$ and $A F G_{2}$ are synthesized from dihydrodimethyl sterigmatocystin in the course of biosynthesis, and that the same enzyme group most probably participates in both these reactions. The course of $A F M_{1}$ and $\mathrm{AF} \mathrm{M}_{2}$ biosynthesis, however, remains unclear. ${ }^{20)}$ These results suggest that $A F M_{1}$ 
TABle I. Production of Aflatoxins and Aflatoxicols by Aspergillus flavus and A. parasiticus

\begin{tabular}{|c|c|c|c|c|c|c|c|c|c|c|c|}
\hline \multirow{2}{*}{ Fungus } & \multirow{2}{*}{$\begin{array}{c}\text { Strain } \\
\text { No. }\end{array}$} & \multirow{2}{*}{ Source } & \multirow{2}{*}{$\begin{array}{l}\text { Incubation } \\
\text { time (d) }\end{array}$} & \multicolumn{6}{|c|}{ Aflatoxins (ng/ml) } & \multicolumn{2}{|c|}{ Aflatoxicols (ng/ml) } \\
\hline & & & & $\mathrm{B}_{1}$ & $\mathrm{~B}_{2}$ & $\mathrm{G}_{1}$ & $\mathrm{G}_{2}$ & $\mathrm{M}_{1}$ & $\mathrm{M}_{2}$ & $\mathrm{~A}$ & $\mathrm{~B}$ \\
\hline \multirow[t]{8}{*}{ Aspergillus flavus } & $A F-144$ & Buckwheat flour & 5 & 2030 & 92.7 & ND & ND & 17.0 & $\operatorname{Tr}$ & ND & ND \\
\hline & & & 10 & 19000 & 1720 & ND & ND & 189 & 12.0 & 2.8 & 1.7 \\
\hline & & & 15 & 23000 & 2170 & ND & ND & 226 & 18.3 & 4.7 & 3.6 \\
\hline & & & 20 & 22800 & 2080 & ND & ND & 237 & 18.1 & 16.3 & 10.7 \\
\hline & $\mathrm{AF}-145$ & Rye flour & 5 & 2130 & 112 & ND & ND & 16.0 & $\operatorname{Tr}$ & ND & ND \\
\hline & & & 10 & 34100 & 3200 & ND & ND & 400 & 30.9 & 2.4 & 1.4 \\
\hline & & & 15 & 37700 & 4030 & ND & ND & 768 & 62.3 & 10.6 & 4.8 \\
\hline & & & 20 & 19400 & 2280 & ND & $\mathrm{ND}$ & 643 & 51.0 & 9.0 & 5.5 \\
\hline \multirow[t]{4}{*}{ "I } & $\mathrm{AF}-146$ & Buckwheat flour & 5 & 3490 & 111 & ND & ND & 16.0 & $\operatorname{Tr}$ & ND & ND \\
\hline & & & 10 & 28400 & 2200 & ND & ND & 280 & 26.2 & 2.5 & 1.4 \\
\hline & & & 15 & 32200 & 3300 & ND & ND & 354 & 38.9 & 10.6 & 8.8 \\
\hline & & & 20 & 29700 & 2850 & ND & $\mathrm{ND}$ & 291 & 22.0 & 19.1 & 12.5 \\
\hline \multirow[t]{4}{*}{$" \prime$} & $A F-147$ & Maize & 5 & 4010 & 124 & ND & ND & 18.5 & $\operatorname{Tr}$ & ND & ND \\
\hline & & & 10 & 13700 & 997 & ND & ND & 111 & $\mathrm{Tr}$ & 3.8 & 2.2 \\
\hline & & & 15 & 28500 & 2740 & ND & $\mathrm{ND}$ & 259 & 17.7 & 6.5 & 2.6 \\
\hline & & & 20 & 22000 & 1860 & ND & ND & 192 & 13.0 & 9.9 & 6.4 \\
\hline \multirow[t]{4}{*}{$"$} & $\mathrm{AF}-149$ & Job's tears & 5 & 2.4 & $\mathrm{ND}$ & ND & ND & ND & ND & ND & $\mathrm{ND}$ \\
\hline & & & 10 & 255 & 7.7 & ND & ND & 2.1 & ND & ND & ND \\
\hline & & & 15 & 281 & 8.2 & ND & ND & 2.5 & ND & ND & ND \\
\hline & & & 20 & 193 & 10.1 & ND & ND & 1.7 & ND & ND & ND \\
\hline \multirow[t]{4}{*}{$" \prime$} & $A F-150$ & Job's tears & 5 & 42300 & 1570 & ND & $\mathrm{ND}$ & 301 & 21.0 & $\operatorname{Tr}$ & ND \\
\hline & & & 10 & 65100 & 3760 & ND & ND & 490 & 29.0 & 20.2 & 7.2 \\
\hline & & & 15 & 92300 & 7200 & ND & ND & 705 & 64.0 & 91.8 & 46.1 \\
\hline & & & 20 & 95200 & 6830 & ND & ND & 726 & 72.8 & 151.2 & 75.9 \\
\hline \multirow[t]{4}{*}{$n$} & $A F-151$ & Buckwheat flour & 5 & 189 & 1.5 & ND & ND & ND & $\mathrm{ND}$ & ND & ND \\
\hline & . & & 10 & 651 & 25.0 & ND & ND & 6.3 & ND & 1.4 & 0.5 \\
\hline & & & 15 & 2210 & 119 & ND & $\mathrm{ND}$ & 29.9 & $\operatorname{Tr}$ & 4.7 & 3.8 \\
\hline & & & 20 & 1060 & 55.4 & ND & $\mathrm{ND}$ & 17.4 & $\operatorname{Tr}$ & 8.7 & 6.3 \\
\hline \multirow[t]{4}{*}{$\prime \prime$} & $A F-152$ & Butter bean & 5 & 1.2 & $\mathrm{ND}$ & ND & ND & ND & ND & ND & ND \\
\hline & & & 10 & 10.8 & 2.4 & ND & ND & ND & ND & ND & ND \\
\hline & & & 15 & 37.4 & 3.0 & ND & ND & ND & ND & ND & ND \\
\hline & & & 20 & 41.8 & 3.5 & ND & ND & ND & ND & ND & ND \\
\hline \multirow[t]{4}{*}{$" 1$} & $A F-153$ & Job's tears & 5 & 213 & 2.6 & ND & ND & $\operatorname{Tr}$ & ND & ND & ND \\
\hline & & & 10 & 290 & 6.0 & ND & ND & 1.6 & ND & ND & ND \\
\hline & & & 15 & 1310 & 24.1 & ND & ND & 9.7 & ND & $\operatorname{Tr}$ & ND \\
\hline & & & 20 & 697 & 16.6 & ND & ND & 6.2 & ND & $\operatorname{Tr}$ & $\operatorname{Tr}$ \\
\hline \multirow[t]{4}{*}{$"$} & $A F-154$ & Peanut & 5 & 34.5 & 2.2 & ND & ND & ND & ND & ND & ND \\
\hline & & & 10 & 5760 & 341 & ND & ND & 53.7 & 4.7 & 5.0 & 2.4 \\
\hline & & & 15 & 6510 & 380 & ND & ND & 62.9 & 4.5 & 11.2 & 9.8 \\
\hline & & & 20 & 4920 & 326 & ND & ND & 40.7 & 3.5 & 15.8 & 13.2 \\
\hline \multirow[t]{4}{*}{$"$} & $A F-155$ & \multirow[t]{4}{*}{ Kidney bean } & 5 & 129 & 5.0 & ND & ND & $\operatorname{Tr}$ & ND & ND & $\mathrm{ND}$ \\
\hline & & & 10 & 5030 & 218 & ND & ND & 53.7 & 2.2 & 1.6 & 0.6 \\
\hline & & & 15 & 5760 & 257 & ND & ND & 68.2 & 3.8 & 1.8 & 1.9 \\
\hline & & & 20 & 5580 & 289 & ND & ND & 68.6 & 3.7 & 7.2 & 6.9 \\
\hline
\end{tabular}

ND: Not detected

$\mathrm{Tr}:<1.0 \mathrm{ng} / \mathrm{ml}$ 
TAble I. Continued

\begin{tabular}{|c|c|c|c|c|c|c|c|c|c|c|c|}
\hline \multirow{2}{*}{ Fungus } & \multirow{2}{*}{$\begin{array}{c}\text { Strain } \\
\text { No. }\end{array}$} & \multirow{2}{*}{ Source } & \multirow{2}{*}{$\begin{array}{l}\text { Incubation } \\
\text { time }(d)\end{array}$} & \multicolumn{6}{|c|}{ Aflatoxins $(\mathrm{ng} / \mathrm{ml})$} & \multicolumn{2}{|c|}{ Aflatoxicols $(\mathrm{ng} / \mathrm{ml})$} \\
\hline & & & & $\mathrm{B}_{1}$ & $\mathrm{~B}_{2}$ & $\mathrm{G}_{1}$ & $\mathrm{G}_{2}$ & $\mathrm{M}_{1}$ & $\overline{M_{2}}$ & $\mathrm{~A}$ & $B$ \\
\hline \multirow[t]{8}{*}{ Aspergillus flavus } & $\mathrm{AF}-156$ & Paprika & 5 & 46.9 & 1.9 & ND & ND & $\operatorname{Tr}$ & ND & ND & ND \\
\hline & & & 10 & 4490 & 158 & ND & ND & 40.1 & $\operatorname{Tr}$ & 1.0 & $\operatorname{Tr}$ \\
\hline & & & 15 & 6550 & 298 & ND & ND & 65.0 & 3.6 & 2.6 & 1.7 \\
\hline & & & 20 & 4080 & 165 & ND & ND & 40.0 & 2.6 & 6.9 & 4.4 \\
\hline & $A F-157$ & Peanut & 5 & 2460 & 169 & ND & ND & 32.0 & $\operatorname{Tr}$ & $\mathrm{ND}$ & ND \\
\hline & & & 10 & 21900 & 2180 & ND & ND & 268 & 40.0 & 1.2 & $\operatorname{Tr}$ \\
\hline & & & 15 & 23100 & 2830 & ND & ND & 299 & 50.8 & 6.0 & 3.6 \\
\hline & & & 20 & 27100 & 3310 & ND & ND & 370 & 63.3 & 17.5 & 12.5 \\
\hline \multirow[t]{4}{*}{ " } & $A F-158$ & Peanut & 5 & 17.8 & ND & ND & ND & ND & ND & ND & ND \\
\hline & & & 10 & 110 & 3.5 & ND & ND & ND & ND & ND & ND \\
\hline & & & 15 & 210 & 18.6 & ND & ND & ND & ND & ND & ND \\
\hline & & & 20 & 189 & 20.7 & ND & ND & ND & ND & ND & ND \\
\hline \multirow[t]{4}{*}{$"$} & $A F-159$ & Nutmeg & 5 & 3.6 & ND & ND & ND & ND & ND & $\mathrm{ND}$ & ND \\
\hline & & & 10 & 1590 & 50.1 & ND & ND & 4.5 & ND & $\operatorname{Tr}$ & ND \\
\hline & & & 15 & 4080 & 157 & ND & ND & 19.1 & ND & $\operatorname{Tr}$ & $\operatorname{Tr}$ \\
\hline & & & 20 & 3730 & 150 & ND & ND & 20.3 & ND & 8.0 & 3.7 \\
\hline \multirow[t]{4}{*}{$"$} & $A F-160$ & Nutmeg & 5 & 40.6 & $\operatorname{Tr}$ & ND & ND & ND & ND & ND & ND \\
\hline & & & 10 & 78.0 & 4.3 & ND & ND & ND & ND & ND & ND \\
\hline & & & 15 & 87.0 & 8.9 & ND & ND & ND & ND & ND & ND \\
\hline & & & 20 & 66.5 & 10.6 & ND & ND & ND & ND & ND & ND \\
\hline \multirow[t]{4}{*}{$"$} & $c-35-a$ & Corn flour & 5 & 10.9 & ND & ND & ND & ND & ND & ND & ND \\
\hline & & & 10 & 642 & 53.1 & ND & ND & 3.5 & ND & ND & ND \\
\hline & & & 15 & 43600 & 1920 & ND & ND & 221 & 9.4 & 60.4 & 49.0 \\
\hline & & & 20 & 47100 & 2830 & ND & ND & 261 & 24.2 & 302 & 264 \\
\hline \multirow[t]{4}{*}{$" 1$} & $C-39-a$ & Corn flour & 5 & 373 & 17.5 & ND & ND & 2.3 & ND & 5.3 & 4.4 \\
\hline & & & 10 & 5510 & 363 & ND & ND & 67.1 & 5.3 & 210 & 210 \\
\hline & & & 15 & 7600 & 442 & ND & ND & 91.0 & 8.4 & 791 & 474 \\
\hline & & & 20 & 7480 & 399 & ND & ND & 70.3 & 8.1 & 980 & 546 \\
\hline \multirow{4}{*}{$\begin{array}{l}\text { Aspergillus } \\
\text { parasiticus }\end{array}$} & $A F-105$ & Pistachio nut & s 5 & 3850 & 175 & 17700 & 919 & 164 & 57.3 & ND & ND \\
\hline & & & 10 & 4730 & 287 & 33600 & 2230 & 323 & 364 & 6.3 & 6.6 \\
\hline & & & 15 & 7380 & 511 & 43600 & 3180 & 414 & 698 & 12.0 & 10.7 \\
\hline & & & 20 & 2770 & 204 & 10700 & 872 & 153 & 68.7 & 8.4 & 6.0 \\
\hline \multirow[t]{4}{*}{$n$} & $A F-120$ & Pistachio nut & s 5 & 126 & 7.7 & 6.0 & $\operatorname{Tr}$ & ND & ND & ND & ND \\
\hline & & & 10 & 872 & 36.4 & 112 & 9.2 & 9.7 & 9.0 & ND & ND \\
\hline & & & 15 & 504 & 24.1 & 59.2 & 5.9 & 5.5 & 3.0 & ND & ND \\
\hline & & & 20 & 133 & 9.4 & 7.7 & $\operatorname{Tr}$ & ND & $\mathrm{ND}$ & ND & $\mathrm{ND}$ \\
\hline \multirow[t]{4}{*}{$\prime \prime$} & $C-41-d$ & Maize & 5 & 209 & 8.7 & 1470 & 67.9 & 8.7 & 7.4 & ND & ND \\
\hline & & & 10 & 483 & 21.9 & 3830 & 210 & 23.2 & 134 & ND & ND \\
\hline & & & 15 & 510 & 35.2 & 2520 & 217 & 49.7 & 176 & ND & ND \\
\hline & & & 20 & 332 & 27.6 & 1570 & 138 & 13.8 & 261 & ND & ND \\
\hline
\end{tabular}

and $\mathrm{AF} \mathrm{M}_{2}$ were not biosynthesized by metabolism from $A F B_{1}$ and $A F B_{2}$, but by other channels from different precursors.

There have been several reports regarding production of $A F B_{1}, A F B_{2}, A F G_{1}, A F$ $\mathrm{G}_{2}, \mathrm{AF} \mathrm{M}_{1}$ and $\mathrm{AF} \mathrm{M}_{2}$ by $A$. flavus and $A$. parasiticus. However, as to the production of
AFL by these fungi, there is only our previous report ${ }^{10)}$ referring to the strain isolated from AFL-contaminated maize. Frequency of isolation of AFL-producing strains has not been determined. In this study using strains of different origins isolated from various foods, AFL was generally produced by AF- 

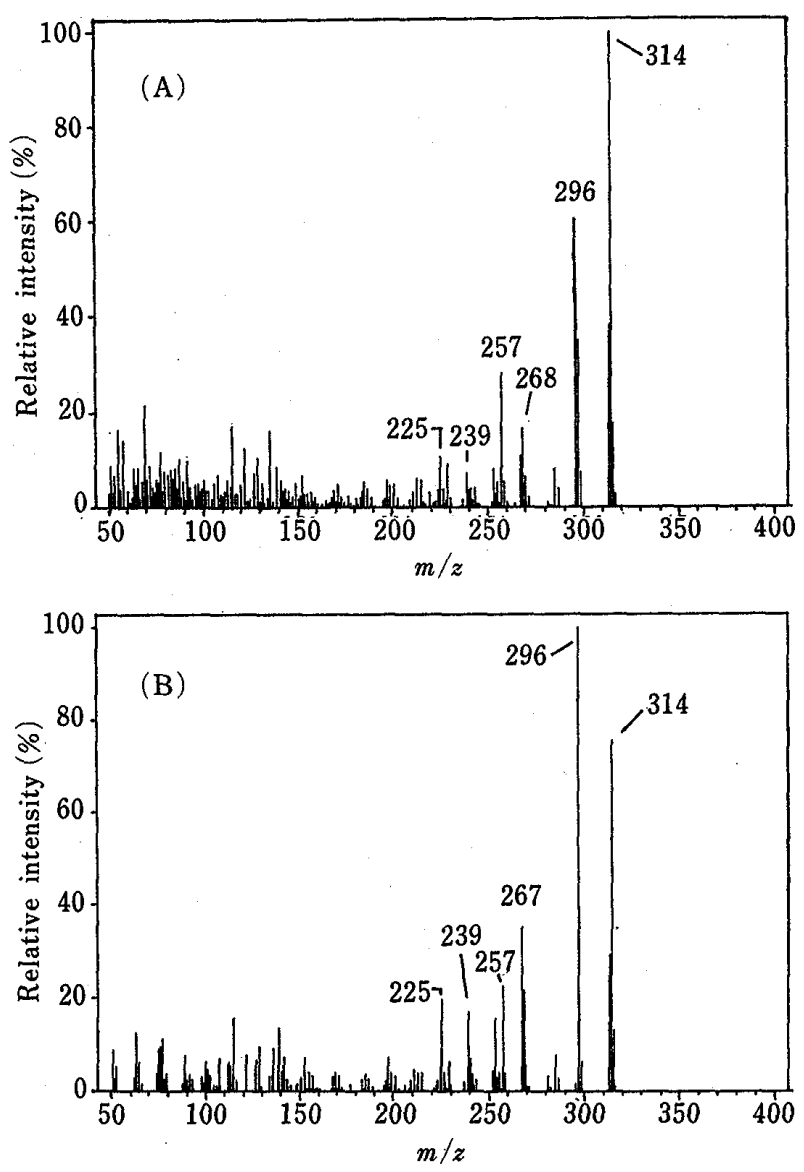

Fig. 4. Mass Spectrum of Aflatoxicols in extracts from cultures inoculated with Aspergillus flavus (AF-150 strain)

(A) : aflatoxicol A, (B) : aflatoxicol B.

producing $A$. flavus. Three out of 18 strains produced comparatively abundant AFL ( $>$ $100 \mathrm{ng} / \mathrm{ml})$, however, in cultures of the other 15 strains, very small quantities of AFL were detected. Moreover, AFL levels in culture tended to increase, although AFs tended to decrease on the 20th day of incubation, and AFLs tended to appear after AFs had accumulated in culture. Trerefore, no correlation between AFL and AF $B_{1}$ production was observed. From this finding, it was presumed that AFLs in cluture were converted from AF $B_{1}$. We found the same result in an AFL productivity test ${ }^{10)}$ using $A$. flavus isolated from AFL-contaminated maize. Confirmation of AFL-A and AFL-B produced by A. flavus was carried out by MS using extracts from cultures of AF-150, C-35-a and C-39-a strains.
AFL-A and AFL-B obtained from a mould culture had mass spectra which corresponded well with that of the reference standard (Fig. 4).

3. Metabolic Conversion of AF $B_{1}$ by NonAF-Producing $A$. flavus

Conversion of $\mathrm{AF} \mathrm{B}_{1}$ to the hydroxide metabolites, $A F M_{1}$, AF $P_{1}$, AF $Q_{1}$ AFL-A and AFL-B, was studied in non-AF-producing A. flavus (Table II).

$\mathrm{AF} \mathrm{B}_{1}$ added to the cultures was metabolized or degraded by all strains. Fifty percent of the $A F B_{1}$ added remained on the 10th day and approximately $25 \%$ on the 20 th day. When $A F B_{1}$ metabolites were analyzed, AFL-A and AFL-B were detected in all of the cultures inoculated with non-AF-producing strains. AFL levels were very low in the cultures of 6 strains, except in that of AF-141 (which had possessed $A F B_{1}$ productivity at initial isolation, but lost it upon subculture), in which approximately $250 \mathrm{ng} / \mathrm{ml}$ of AFLs was detected on the 15th day of incubation. This corresponded with about $12 \%$ of the AF $B_{1}$ added. However, on the 20th day of incubation, AFL levels were reduced in nearly all the strains (5 strains), which indicates that the produced AFL was incorporated by the fungi for further metabolism. These facts support the aforementioned hypothesis that AFLs manufactured by the AF-producing $A$. flavus were converted from $A F B_{1}$ by its own metabolic sequences. $A F M_{1}, A F P_{1}$ and $A F Q_{1}$, however, were not detected from any cultures of any strain.

From our metabolic studies of $\mathrm{AF} \mathrm{B}_{1}$ using non-AF-producing strains, only one strain out of 7 was capable of converting AF $\mathrm{B}_{1}$ to AFL. Further, in AF-producing strains, 3 out of 18 produced AFL comparatively abundantly. This corresponded to approximately $17 \%$ of tested AF-producing strains. 
TABLE II. Conversion of Aflatoxin $\mathrm{B}_{1}$ to Aflatoxicons by Non-Aflatoxin-Producing Aspergillus flavus $(\mathrm{ng} / \mathrm{ml})$

\begin{tabular}{|c|c|c|c|c|c|}
\hline \multirow{2}{*}{$\begin{array}{l}\text { Strain } \\
\text { No. }\end{array}$} & \multirow{2}{*}{ Source } & \multirow{2}{*}{$\begin{array}{l}\text { Incubation } \\
\text { time }(d)\end{array}$} & \multirow{2}{*}{$\begin{array}{l}\text { Residual amount } \\
\text { of aflatoxin } B_{1}\end{array}$} & \multicolumn{2}{|c|}{ Detected amount of aflatoxicols } \\
\hline & & & & $\mathrm{A}$ & $\mathrm{B}$ \\
\hline \multirow[t]{4}{*}{$\mathrm{AF}-141$} & Biscuit & 5 & 1600 & 33.5 & 37.7 \\
\hline & & 10 & 827 & 87.3 & 102.5 \\
\hline & & 15 & 707 & 136.0 & 115.7 \\
\hline & & 20 & 662 & 95.7 & 99.6 \\
\hline \multirow[t]{4}{*}{$\mathrm{AF}-142$} & Buckwheat flour & 5 & 1530 & 2.8 & 1.9 \\
\hline & & 10 & 1080 & 4.2 & 2.6 \\
\hline & & 15 & 564 & 18.1 & 5.1 \\
\hline & & 20 & 357 & 10.8 & 2.4 \\
\hline \multirow[t]{4}{*}{$\mathrm{AF}-143$} & Bread & 5 & 1220 & 1.3 & $\operatorname{Tr}$ \\
\hline & & 10 & 786 & 13.3 & 4.0 \\
\hline & & 15 & 525 & 7.7 & 2.6 \\
\hline & & 20 & 515 & 6.3 & 3.4 \\
\hline \multirow{4}{*}{$\mathrm{AF}-148$} & Nutmeg & 5 & 1540 & 1.2 & $\operatorname{Tr}$ \\
\hline & & 10 & 1230 & 18.1 & 6.0 \\
\hline & . & 15 & 912 & 21.7 & 6.4 \\
\hline & & 20 & 510 & 11.7 & 4.4 \\
\hline \multirow[t]{4}{*}{$C-40-e$} & Maize & 5 & 1230 & 2.1 & $\operatorname{Tr}$ \\
\hline & & 10 & 963 & 1.8 & 1.0 \\
\hline & & 15 & 745 & 13.5 & 8.2 \\
\hline & & 20 & 469 & 5.2 & 1.5 \\
\hline \multirow[t]{4}{*}{$C-40-f$} & Maize & 5 & 1120 & 2.0 & 2.1 \\
\hline & & 10 & 850 & 5.2 & 5.8 \\
\hline & & 15 & 710 & 4.1 & 2.6 \\
\hline & & 20 & 625 & 9.9 & 3.4 \\
\hline \multirow[t]{4}{*}{$C-40-j$} & Maize & 5 & 1306 & 1.7 & 1.6 \\
\hline & & 10 & 855 & $\operatorname{Tr}$ & $\operatorname{Tr}$ \\
\hline & & 15 & 764 & 6.0 & 3.7 \\
\hline & & 20 & 456 & 7.3 & 3.3 \\
\hline
\end{tabular}

$\operatorname{Tr}: 1.0 \mathrm{ng} / \mathrm{ml}$

\section{References}

1) R.J. Cole and R.H. Cox (eds.), Handbook of Toxic Fungal Metabolites," Academic Press, New York, 1981, pp.1-66.

2) M.P. Doyle, R.S. Applebaum, R.E. Brackett and E.H. Marth, J. Food Prot., 45, 964 (1982).

3) M.P. Doyle and E.H. Marth, Z. Lebensm. Unters. Forsch. 166, 271 (1978).

4) H. Tsubouchi, K. Yamamoto, K. Hisada, Y. Sakabe and K. Tsuchihira, Proc. Jpn. Assoc. Mycotoxicol., 12, 33 (1980).

5) R.W. Detroy and C.W. Hesseltine, Can. J. Microbiol., 15, 495 (1969).

6) R.J. Cole, J.W. Kirksey and B.R. Blankenship, J. Agric. Food Chem., 20, 1100 (1972).

7) R. Mann and H.J. Rehm, Eur. J. Appl. Microbiol., 2, 297 (1976).

8) M. Nakazato, K. Saito, Y. Kikuchi, A. Ibe, K. Fujinuma, M. Nishijima, Y. Naoi, T. Nishima, S. Morozumi, T. Wauke and H. Hitokoto, J. Food Hyg. Soc. Jpn. 26, 33 (1985).

9) K. Saito, M. Nishijima, K. Yasuda, H. Kamimura, A. Ibe, T. Nagayama, H. Ushiyama and Y. Naoi, J. Food Hyg. Soc. Jpn., 25, 241 (1984). 
10) M. Nakazato, K. Saito, Y. Kikuchi, A. Ibe, K. Fujinuma, M. Nishijima, T. Nishima, S. Morozumi, T. Wauke and H. Hitokoto, J. Food Hyg. Soc. Jpn. 26, 380 (1985).

11) T.V. Reddy, L. Viswanathan and T.A. Venkitasubramanian, Appl. Microbiol., 22, 393 (1971).

12) M. Manabe, Proc. Jpn. Assoc. Mycotoxicol., 17, 17 (1983).

13) The Pharmaceutical Society of Japan (ed.), "Standard Methods of Analysis for Hygienic Chemists ; With Commentary," Kanehara shuppan, Tokyo, 1990, pp.404-407.

14) The Association of Official Analytical Chemists (ed.) 49. Natural Poisons in "Changes in Official Methods of Analysis," J. Assoc. Off. Anal Chem., 73, 191 (1990).

15) D.L. Park, S. Neshim, M.W. Trucksess, M.E. Stack and R.F. Newell, J. Assoc. Off. Anal Chem., 73, $260(1990)$.

16) M. Manabe, T. Goto, and S. Matsuura, Agric. Biol. Chem., 42, 2003 (1978).

17) K. Saito, M. Nishijima, K. Yasuda, H. Kamimura, A.Ibe, T. Nagayama, H. Ushiyama and Y. Naoi, J. Food Hyg. Soc. Jpn. 25, 112 (1984).

18) K. Yabe, Y. Ando and T. Hamasaki, Appl. Environ. Microbiol., 54, 2101 (1988).

19) K. Yabe, Y. Ando, J. Hashimoto and T. Hamasaki, Appl. Environ. Microbiol., 55, 2172 (1989).

20) M.F. Dutton, Microbiol. Rev., 52, 274 (1988). 